\title{
Pengaruh Penambahan Sampah Organik, Bioaktivator dan Fases Hewan Pada Lubang Resapan Biopori (LRB) Terhadap Infiltrasi dan Permeabilitas Tanah
}

\author{
Yayu Sriwahyuni ${ }^{1)}$, Cilda Thesisa Ilmawan Dzinnur ${ }^{2)}$, Satria Agung Wibawa ${ }^{3)}$ \\ 1) 2) Fakultas Teknik, Program Studi Teknik Sipil, Universitas Sunan Giri Surabaya, Jl. Brigjen Katamso \\ II Waru Sidoarjo; Telp. 031-8532477. \\ Email: yayu.sriwhy@gmail.com ,bataranaradajaya@gmail.com \\ 3) Fakultas Teknik, Program Studi Teknik Sipil, Universitas Veteran Bangun Nusantara, Sukoharjo, \\ Jl. Letjen Sudjono Humardhani, No.1, Jombor, Sukoharjo; Telp. 0271-593156. \\ Email: sagungwibawa@gmail.com
}

\begin{abstract}
Abstrak
Dengan berkurangnya Ruang Terbuka Hijau (RTH) di daerah perkotaan, maka teknologi Lubang Resapan Biopori (LRB) merupakan salah satu teknologi alternatif eco drainage yang dapat diterapkan untuk menanggulangi banjir, membantu mengurangi kekeringan serta mengurangi beban sampah kota. Selain menggunakan sampah organik sebagai media pengisi Lubang Resapan Biopori (LRB) juga digunakan bahan bioaktivator dan fases hewan sebagai bahan campuran. Tujuan dari penelitian ini yaitu untuk mengetahui pengaruh sampah organik, bioaktivator dan fases hewan terhadap infiltrasi pada Lubang Resapan Biopori (LRB) serta untuk mengetahui permeabilitas yang terjadi di sekitar LRB pada minggu ke-4. Dari hasil data pengujian, analisa data dan pembahasan, dapat ditarik kesimpulan bahwa sampah organik, bioaktivator dan fases hewan berpengaruh pada peningkatan infiltrasi. Ratarata peningkatan infiltrasi pada LRB1 (sampah organik) sebesar 6,831 cm/detik, LRB2 (sampah organik+fases hewan) sebesar 6,888 cm/detik, LRB3 (sampah organik+bioaktivator) sebesar 7,175 cm/detik. Sampah organik, fases hewan dan bioaktivator juga secara langsung mampu mempengaruhi permeabilitas tanah di sekeliling LRB walaupun tidak terlalu signifikan. Nilai tertinggi permeabilitas terjadi pada blanko-blanko yang terletak dekat dengan LRB, yaitu blanko 1A, 2A dan 3A dengan nilai 0,017681 cm/detik; 0,017582 cm/detik; 0,017979 cm/detik.
\end{abstract}

Kata kunci: lubang resapan biopori, infiltrasi, permeabiltas.

\begin{abstract}
With the reduction of Green Open Space (RTH) in urban areas, the Biopore Infiltration Hole (LRB) technology is one of the alternative eco-drainage technologies that can be applied to tackle flooding, help reduce drought and reduce the burden of municipal waste. Apart from using organic waste as a filling medium for Biopore Infiltration Holes $(L R B)$, bioactivators and animal fases are also used as a mixture. The purpose of this study was to determine the effect of organic waste, bioactivators and animal fases on the infiltration of the Biopore Infiltration Hole (LRB) and to determine the permeability that occurred around LRB at week-4. From the results of the test data, data analysis and discussion, it can be concluded that organic waste, bioactivators and animal fases have an effect on increasing infiltration. The average increase in infiltration in LRB1 (organic waste) was $6,831 \mathrm{~cm} / \mathrm{second}$, LRB2 (organic waste + animal fases) was $6,888 \mathrm{~cm} /$ second, LRB3 (organic waste + bioactivator) was 7,175 cm / second. Organic waste, animal fases and bioactivators are also able to directly affect the permeability of the soil around the LRB, although it is not very significant. The highest permeability values occurred in the blanks located close to the LRB, namely blanks $1 A, 2 A$ and $3 A$ with a value of $0.017681 \mathrm{~cm}$
\end{abstract}

Keywords: biopore infiltration holes, infiltration, permeability.

\section{PENDAHULUAN}

Teknologi Lubang Resapan Biopori (LRB) merupakan salah satu teknologi alternatif eco drainage yang dapat diterapkan walaupun terbentur dengan minimnya lahan yang disebabkan padatnya pemukiman dan gedung gedung. LRB dapat menanggulangi banjir untuk daerah yang sudah mulai berkurang daerah resapan airnya (Juliandari dkk, 201) selain itu LRB dapat membantu mengurangi kekeringan serta mengurangi beban sampah kota. Teknologi LRB dapat dibuat dengan mudah, biaya yang murah, tidak memerlukan lahan yang luas serta cepat dalam proses pembuatannya. LRB sangat tepat bila diterapkan pada wilayah yang mempunyai 
kepadatan bangunan dan pemukiman penduduk (Elsie, 2017 dan Martha, 2018).

Dalam proses pembuatan lubang resapan biopori diperlukan penambahan sampah organik ke dalam lubang resapan. Sampah organik yang dimasukkan ke dalam lubang resapan biopori akan dimanfaatkan oleh organisme tanah sebagai sumber bahan makanan (Iswahyudi, 2010). Mobilitas organisme tanah dalam lubang resapan biopori secara langsung akan membentuk liang / pori pori tanah yang bercabang - cabang sehingga secara efektif dapat menyalurkan air ke dalam tanah (Maria, 2014). Semakin banyak pori pori yang dibuat oleh organisme tanah, maka kemampuan tanah dalam meresapkan air juga akan semakin meningkat. Proses masuknya air dari atas (surface) kedalam tanah disebut infiltrasi (f). Sedangkan laju infiltrasi (ft) adalah daya infiltrasi maksimum yang ditentukan oleh kondisi permukaan termasuk lapisan atas dari tanah. Dengan kata lain, infiltrasi adalah perjalanan air ke dalam tanah sebagai akibat gaya kapiler (gerakan air ke arah lateral) dan gravitasi (gerakan air ke arah vertikal).

Pemanfaatan sifat fisik tanah yaitu permeabilitas tanah (k) untuk mengukur cepat lambatnya air melewati pori-pori tanah dapat digunakan untuk menentukan harga resapan air tanah (Christady, 2010). Menurut M Juandi dan S Syahril (2017) bahwa tanah yang berbeda akan memiliki permeabilitas yang berbeda pula. Sedangkan untuk klasifikasi permeabilitas tanah menurut Uhland dan O'Neil dalam LPT, (1979) dapat disajikan pada Tabel dibawah ini.

Tabel 1. Klasifikasi Permeabilitas Tanah

\begin{tabular}{|c|l|c|}
\hline No & \multicolumn{1}{|c|}{ Kelas } & Permeabilitas (cm/jam) \\
\hline 1 & Sangat lambat & $<0,125$ \\
2 & Lambat & $0,125-0,50$ \\
3 & Agak lambat & $0,50-2,00$ \\
4 & Sedang & $2,00-6,25$ \\
5 & Agak cepat & $6,25-12,50$ \\
6 & Cepat & $12,50-25,00$ \\
7 & Sangat cepat & $>25,00$ \\
\hline
\end{tabular}

Untuk menentukan hubungan permeabilitas tanah dengan koefisien resapan tanah berdasarkan deskripsi cepat atau lambatnya air merembes ke dalam pori-pori tanah,dapat dilihat pada tabel berikut:
Tabel 1.2 Hubungan permeabilitas dengan nilai koefisien resapan tanah

\begin{tabular}{|c|l|c|l|c|}
\hline No & \multicolumn{1}{|c|}{ Permeabilitas } & Koefisien resapan & \multicolumn{1}{|c|}{ Deskipsi } & Nilai \\
\hline 1 & Cepat (>30) & 0,3 & Sangat tinggi & 5 \\
2 & Agak cepat $(15-30)$ & 0,25 & Tinggi & 4 \\
3 & Sedang - cepat $(7-15)$ & 0,15 & Sedang & 3 \\
4 & Agak lambat $(2-7)$ & 0,1 & Rendah & 2 \\
5 & Lambat (<2) & 0 & Sangat rendah & 1 \\
\hline
\end{tabular}

Pada penelitian ini selain hanya menggunakan sampah organik sebagai media pengisi Lubang Resapan Biopori (LRB) juga digunakan bahan bioaktivator dan fases hewan sebagai bahan campuran. Penambahan bahan bioaktivator dan fases hewan diharapkan dapat meningkatkan proses dekomposisi sampah organik yang nantinya akan diteliti apakah proses pencampuran ini dapat berpengaruh terhadap laju infiltrasi dan permeabilitas tanah disekitar lubang resapan.

Sehingga secara garis besar tujuan dari penelitian ini yaitu untuk mengetahui pengaruh sampah organik, bioaktivator dan fases hewan terhadap infiltrasi pada Lubang Resapan Biopori (LRB) dan untuk mengetahui permeabilitas yang terjadi di sekitar LRB pada minggu ke-4.

\section{METODE}

\section{Bahan dan Alat}

Bahan utama yang digunakan dalam penelitian ini adalah pipa paralon diameter 4" panjang 80 cm sebanyak 12 buah (LRB1, LRB2, LRB3 dan blanko 1A, 1B, 1C, blanko 2A, 2B, 2C, blanko $3 \mathrm{~A}, 3 \mathrm{~B}, 3 \mathrm{C}$ ) yang berfungsi untuk menjaga agar tanah dalam lubang tidak amblas. Untuk bahan/material pengisi LRB digunakan sampah organik berupa daun dan ranting kering, fases kambing serta bahan merk EM 4 untuk bioaktivator. Pembagian bahan/material isian LRB sebagai berikut:

- LRB1 (sampah organik)

- LRB2 (sampah organik + fases)

- LRB3 (sampah organik + bioaktivator)

Khusus alat utama yang digunakan adalah alat bor LRB dengan mata bor khusus untuk jenis tanah berbutiran halus yang berfungsi untuk membuat lubang pada tanah guna pemasangan LRB. 


\section{Metode penelitian}

Pemasangan LRB dilakukan di satu lokasi. Dengan jarak sebagai berikut:

- Jarak antara LRB1, LRB2 dan LRB3 sejauh $1,00 \mathrm{~m}$

- Jarak antara blanko 1A, 1B, 1C adalah $0,3 \mathrm{~m}, 0,6 \mathrm{~m}$, dan $1,00 \mathrm{~m}$ dari LRB1

- Jarak antara blanko 2A, 2B, 2C adalah $0,3 \mathrm{~m}, 0,6 \mathrm{~m}$, dan $1,00 \mathrm{~m}$ dari LRB2

- Jarak antara blanko 3A, 3B, 3C adalah $0,3 \mathrm{~m}, 0,6 \mathrm{~m}$, dan $1,00 \mathrm{~m}$ dari LRB3

Nilai infiltasi (f) pada LRB1, LRB2, dan LRB3 diperoleh berdasarkan pengukuran waktu $(\mathrm{t})$ pada setiap penurunan muka air $(\mathrm{h}=5 \mathrm{~cm})$. Pengukuran dilakukan setiap 7 hari selama satu bulan.

Pengukuran nilai permeabilitas (k), semua blanko yang sudah terpasang diisi dengan air sebanyak 30 lt, kemudian di ukur waktu (t) pada setiap penurunan (h) $5 \mathrm{~cm}$. Selanjutnya di ukur diameter blanko (d), panjang blanko (L) serta perubahan ketinggian muka air (h1; h2). Untuk penentuan nilai permeabilitas (k) di lapangan menggunakan persamaan (Hvorslev, 1951):

$$
k=\frac{d^{2}}{8 L t} \ln \left(\frac{2 L}{d}\right) \ln \left(\frac{h 1}{h 2}\right)
$$

\section{HASIL DAN PEMBAHASAN}

Hasil Analisis data menggunakan statistik deskriptif dengan cara mendeskripsikan data yang telah terkumpul. Penyajian data dalam statistik deskriptif melalui tabel dan diagram grafik. Uji peresapan air/infiltrasi dan permeabilitas tanah dilakukan di Desa Sedati Gede Kecamatan Sedati Kabupaten Sidoarjo.

1. Pengaruh Sampah Organik, Bioaktivator dan Fases Hewan Terhadap Infiltrasi LRB $1,2,3$

Pada penelitian ini, dapat dilihat bahwa bahan isian LRB 3 memiliki tingkat infiltrasi yang tinggi pada minggu ke-1 dan ke-2 dibanding dengan LRB 1 dan LRB 2, yaitu sebesar 7,400 $\mathrm{cm} /$ detik dan 7,575 $\mathrm{cm} /$ detik. Tetapi pada saat mencapai minggu ke-4, terjadi penurunan infiltrasi yang cukup signifikan pada LRB 3 . Infiltrasi yang di hasilkan sangat rendah dibanding LRB lainnya, yaitu sebesar 6,500 $\mathrm{cm} /$ detik. Hal ini disebabkan karena proses dekomposisi sampah organik tidak lagi terjadi pada minggu ke-4, dikarenakan bahan bioaktivator yang digunakan sebagai campuran sampah organik pada LRB 3 mampu mempercepat proses dekomposisi tersebut. Untuk infiltrasi pada LRB 2 tidak jauh berbeda dengan infiltrasi pada LRB 1.

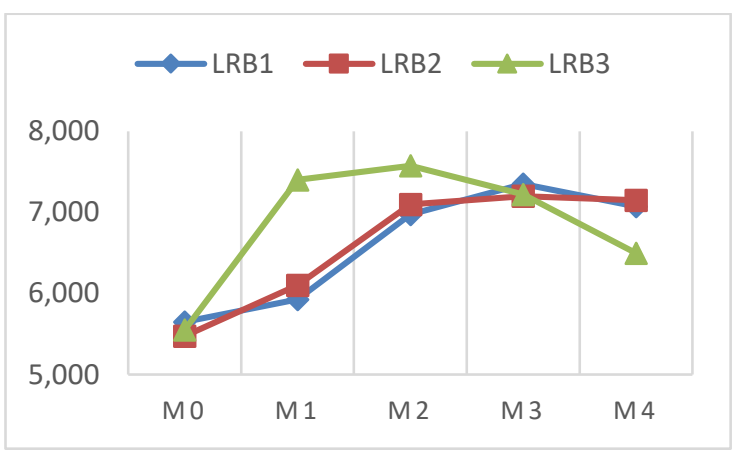

Gambar 1. Grafik Pengaruh Sampah Organik,

Bioaktivator dan Fases Hewan Terhadap

LRB 1,2,3

2. Pengaruh Sampah Organik, Bioaktivator dan Fases Hewan Terhadap Permeabilitas Tanah di Sekeliling LRB

Dari hasil pengamatan dapat dilihat bahwa sebaran nilai permeabilitas tanah di sekitar LRB cenderung menunjukkan bahwa semakin mendekati lubang resapan (LRB) nilai permeabilitas tanah cenderung meningkat. Nilai permeabilitas yang terbentuk antara tiap blanko tidak menunjukan angka yang berbeda secara signifikan. Ini dikarenakan pengaruh struktur dan jenis tanah yang sama karena berada dalam satu lokasi penelitian. Berdasarkan tabel klasifikasi permeabilitas tanah menurut Uhland dan O'Neil dalam LPT, (1979) nilai permeabilitas yang diperoleh dalam penelitian ini masuk dalam klasifikasi sangat cepat > $25,00 \mathrm{~cm} / \mathrm{jam}$. Nilai permeabilitas (k) setiap blanko dapat dilihat pada diagram di bawah ini:

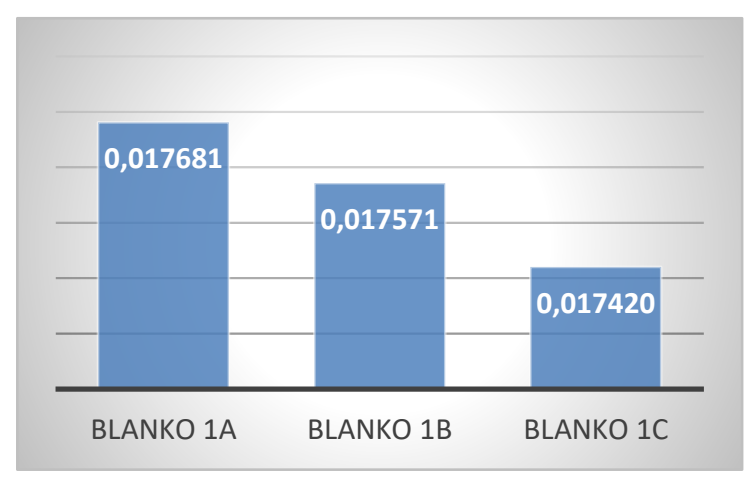

Gambar 2. Permeabilitas Pada Blanko 1A,1B dan 1C 


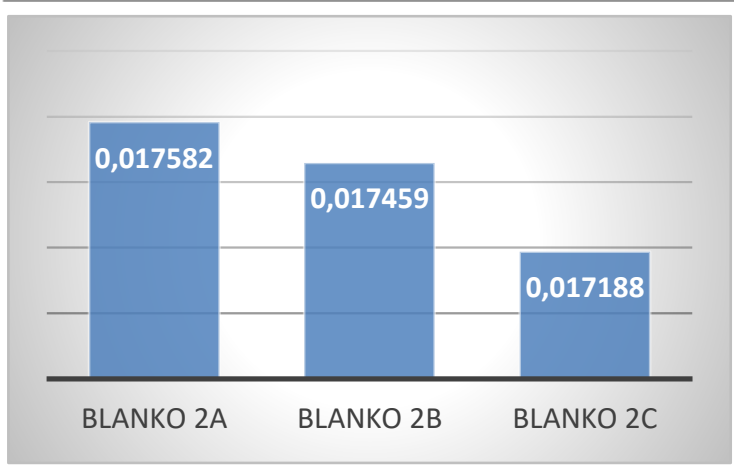

Gambar 3. Permeabilitas Pada Blanko 2A, 2B dan 2C

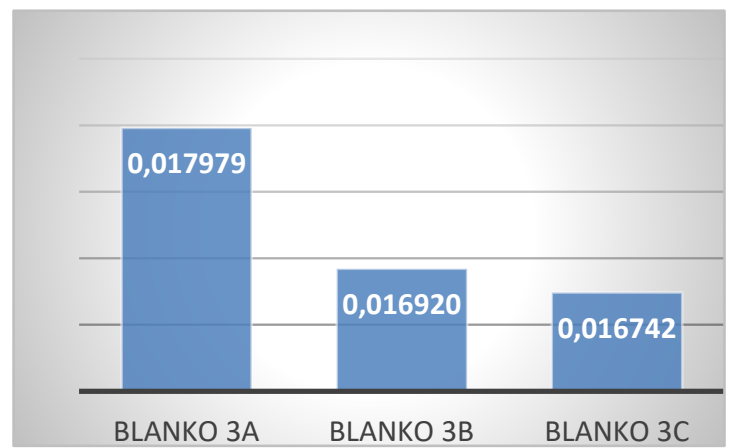

Gambar 4. Permeabilitas Pada Blanko 3A, 3B dan 3C

\section{SIMPULAN}

Dari hasil data pengujian, analisa data dan pembahasan, dapat ditarik kesimpulan bahwa sampah organik, bioaktivator dan fases hewan berpengaruh pada peningkatan infiltrasi. Ratarata peningkatan infiltrasi pada LRB1 (sampah organik) sebesar $6,831 \mathrm{~cm} /$ detik, LRB2 (sampah organik+fases hewan) sebesar $6,888 \mathrm{~cm} /$ detik, LRB3 (sampah organik+bioaktivator) sebesar $7,175 \mathrm{~cm} /$ detik.

Sampah organik, fases hewan dan bioaktivator juga secara langsung mampu mempengaruhi permeabilitas tanah di sekeliling LRB walaupun tidak terlalu signifikan. Nilai tertinggi permeabilitas terjadi pada blankoblanko yang terletak dekat dengan LRB, yaitu blanko 1A, 2A dan 3A dengan nilai 0,017681 cm/detik; 0,017582 cm/detik; 0,017979 $\mathrm{cm} /$ detik.

\section{UCAPAN TERIMAKASIH}

Ucapan terima kasih terutama ditujukan kepada Universitas Sunan Giri Surabaya atas dukungannya dalam pelaksanaan penelitian ini.

\section{SIMPULAN}

Kesimpulan menggambarkan jawaban dari hipotesis danatau tujuan penelitian atau temuan ilmiah yang diperoleh. Kesimpulan bukan berisi perulangan dari hasil dan pembahasan, tetapi lebih kepada ringkasan hasil temuan seperti yang diharapkan di tujuan atau hipotesis. Bila perlu, di bagian akhir kesimpulan dapat juga dituliskan hal-hal yang akan dilakukan terkait dengan gagasan selanjutnya dari penelitian tersebut. Kesimpulan ditulis dalam paragraf utuh, bukan poin per poin.

\section{UCAPAN TERIMAKASIH}

Ucapan terima kasih terutama ditujukan kepada Universitas Sunan Giri Surabaya atas dukungannya dalam pelaksanaan penelitian ini.

\section{DAFTAR PUSTAKA}

Brata, K. R. 2008. Implementasi Sistem Peresapan Biopori Untuk Konservasi Sumber Daya Air. 9 Februari 2008. Jakarta

Christady, Hary Hardiyatmo, 2010. Mekanika Tanah 1, Gadjah Mada University Press

Dasar Pertanian, 2016. Manfaat EM-4 Terhadap Kesuburan Tanah dan Tanaman. http://dasarpertanian.blogspot.com/2016/09/in ilah-manfaat-em-4-terhadap-kesuburan.html

Elsie, I. Harahap, N. Herlina, Y. Badrun, N. Gesriantuti. 2017. Pembuatan Lubang Resapan Biopori Sebagai Alternatif Penanggulangan Banjir di Kelurahan Maharatu Kecamatan Marpoyan Damai Pekanbaru. Jurnal Untuk Mu Negeri. Vol. 1. No.2. ISSN : 2550-0198.

Iswahyudi, Dian. 2010. Teknik Pembuatan Kompos Kombinasi Kotoran Sapi dan Limbah Organik dengan Pemberian EM-4. Jember: Jurusan Teknik Pertanian, Fakultas Teknologi Pertanian, Universitas Jember.

Juliandari, Murti, Nirmala Azwa, Yuniarti Erni, 2013, Efektivitas Lubang Resapan Biopori Terhadap Laju Resapan (Infiltrasi), Fakultas Teknik, Universitas Tanjungpura, https://www.neliti.com/id/publications/19134 5/efektivitas-lubang-resapan-bioporiterhadap-laju-resapan-infiltrasi

LPT (Lembaga Penelitian Tanah). 1979. Penuntun Analisa Fisika Tanah. Bogor: Badan Penelitian dan Pengembangan Pertanian. 
Martha, Luluk, 2018. Studi Air Hujan Melalui Lubang Resapan Biopori (LRB) Sebagai Upaya Mereduksi Beban Drainase di Universitas Islam Negeri Sunan Ampel Surabaya, Fakultas Sains dan Teknologi, Universitas Islam Negeri Sunan Ampel, Surabaya.

Maria, Dyah Rose, 2014, Pengaruh Trichoderma sp. Dan Molase pada Pengomposan Sampah Daun Dalam Lubang Resapan Biopori Terhadap Laju Pengomposan dan Laju Peresapan Air, Fakultas Pertanian, Institut Pertanian Bogor, Bogor. https://123dok.com/document/8yd1kojypenga ruh-trichoderma-pengomposan-resapanbiopori-terhadap-pengomposanperesapan.html

Malik, Usman, Gunawan Indra, Juandi, 2018. Analisa Tingkat Resapan Tanah Berdasarkan Pengukuran Permeabilitas Tanah (Studi Kasus Kecamatan Tampan Kota Pekanbaru), Jurusan Fisika FMIPA. Universitas Riau,
Pekanbaru, Jurnal Komunikasi Fisika Indonesia, Edisi April 2018 | Vol. 15, No. 01 | p ISSN.1412- 2960 | e-2579-521X

M Juandi, R Syech , 2018. The Ground Water Recharge Based on The Value of Soil Permeability,- Applied Science and Technology, Volume 2, Issue 1.

Permatasari, Laras. 2015. Biopore Infiltration Hole: "One Day For Biopore" As An Alternative Prevent Flood. International Journal of Advances in Science Engineering and Technology. Volume 3. Issue 2. ISSN: 2321- 9009.

Sibarani, R.T dan Didik Bambang, Penelitian Biopori Untuk Menentukan Laju Resap Air Berdasarkan Variasi Umur dan Jenis Sampah, Jurusan Teknik Lingkungan FTSP-ITS, Surabaya http://digilib.its.ac.id/public/ITSUndergraduate-10743-Paper.pdf 